Short Communication

\title{
Electrochemical Corrosion Behaviour of Carbon Steel Reinforcement in Metakaolin-Limestone Modified Concrete Exposed to Simulated Soil Solution
}

\author{
Yun Ma, Dawei Yuan*, Chun Han
}

School of Civil Engineering and architecture, Xinxiang College, Xinxiang 453003, P.R. China *E-mail: yuandawei111@xxu.edu.cn

doi: $10.20964 / 2021.05 .23$

Received: 18 December 2020 / Accepted: 24 February 2021 / Published: 31 March 2021

Due to environmental and technical needs, partial replacement of cement using pozzolanic materials in concrete structures has received much attention from researchers. In this work, an experimental research was done to study the durability and corrosion resistance of carbon steel rebar in MetakaolinLimestone (MKLF) modified concrete exposed to simulated soil solution. The present work considered the electrochemical corrosion behavior of carbon steel rebar in simulated soil with and without chloride using open circuit potential, electrochemical impedance spectroscopy and polarization tests. Electrochemical measurements indicated that the addition of MKLF enhances corrosion resistance, decreases the corrosion rate and delays corrosion onset. This improvement in concrete structure can be related to the decrease of the concrete permeability.

Keywords: Metakaolin-Limestone modified concrete; Electrochemical corrosion resistance; Simulated soil solution; Carbon steel rebar

\section{$\underline{\text { FULL TEXT }}$}

(C) 2021 The Authors. Published by ESG (www.electrochemsci.org). This article is an open access article distributed under the terms and conditions of the Creative Commons Attribution license (http://creativecommons.org/licenses/by/4.0/). 